Bangladesh J. Plant Taxon. 22(2): 67-75, 2015 (December)

\title{
GENETIC DIVERSITY AND INTERSPECIFIC RELATIONSHIPS OF SOME ALLIUM L. SPECIES USING INTER SIMPLE SEQUENCE REPEAT MARKERS
}

\author{
LEILA SAMIEI $^{1}$, MAHNAZ KiANI, HOMA ZARGHAMI, FARSHID MEMARIANI ${ }^{2}$ AND \\ MOHAMMAD REZA JOHARCHI ${ }^{2}$ \\ Department of Ornamental Plants, Research Center for Plant Sciences, \\ Ferdowsi University of Mashhad, Mashhad, Iran
}

Keywords: Allium L.; Genetic relationship; ISSR; Molecular marker.

\begin{abstract}
In this study genetic diversity and interspecific relationships of 11 Allium L. species from Khorassan province of Iran including 32 accessions were investigated by inter simple sequence repeat (ISSR) markers. Nine ISSR primers produced a total of 80 polymorphic markers and revealed high polymorphism among the studied species. The average gene diversity, effective number of alleles and Shannon's information index were $0.2,1.28$ and 0.3 , respectively. Allium kuhsorkhense exhibited the greatest level of variation $\left(\mathrm{H}_{\mathrm{e}}: 0.18\right)$, whereas $A$. stipitatum demonstrated the lowest level of variability $\left(\mathrm{H}_{\mathrm{e}}: 0.05\right)$. UPGMA (Unweighted Pair Group Method with Arithmetic mean) analysis showed that Allium accessions have a similarity range of 0.60 to 0.95 . Allium scapriscapum composed the most distant group in the dendrogram. The clustered groups of Allium species clearly reflect the recent taxonomic concept of the genus at the subgenus and section levels. The present study showed that the ISSR technique is an effective molecular approach for analyzing genetic diversity and relationship in Allium species.
\end{abstract}

\section{Introduction}

The genus Allium L. is a member of Amaryllidaceae (APG III, 2009), subfamily Allioideae, tribe Allieae (Chase et al., 2009; Reveal and Chase, 2011). It is one of the largest genera of monocots and comprises more than 900 species naturally occurring in the Northern Hemisphere (Fritsch and Abbasi, 2013). This genus has a main centre of diversity in the eastern Mediterranean area as well as southwest and central Asia (Fritsch and Friesen, 2002). Allium is a typical genus for Irano-Turanian floristic region and displays a high level of specific endemism there (Matin, 1992). There are nearly 50 Allium species, which are cultivated widely in the world and many more wild species are utilized locally for human consumption as spices, vegetables, medicinal and ornamental plants (Friesen et al., 2006).

Allium consists of perennial herbs mostly characterized by tunicate bulbs, narrow basal leaves, umbellate or head-like inflorescences, flowers with 6 free or almost free tepals, and an onion-like odour and taste due to the presence of cystine sulphoxides (Li et al., 2010). Many studies assessing morphological and anatomical characters of Allium species have been performed and numerous data have so far been published (Friesen, 1995; Mathew, 1996; Fritsch and Friesen, 2002; Kovtonyuk et al., 2009). However, due to the close morphological similarities of the species, over reliance on dried specimens, and high degree of polymorphism of specific morphological traits (Khassanov and Fritsch, 1994; Mes et al., 1997), many gaps still remain in

\footnotetext{
${ }^{1}$ Corresponding author. Email: samiei@um.ac.ir

${ }^{2}$ Department of Botany, Research Center for Plant Sciences, Ferdowsi University of Mashhad, Mashhad, Iran.
} 
our knowledge of infrageneric taxonomy and differentiation and evolution in the genus (Rabinowitch and Brewster, 1990; Rabinowitch and Currah, 2002).

DNA-based molecular markers have been used previously in the studies of genetic diversity and phylogenetic analysis of Allium (Mes et al., 1999; Friesen et al., 2006; Gurushidze et al., 2008; Mukherjee et al., 2013). Of the different molecular markers, inter sample sequence repeat (ISSR) marker has been widely used to access species genetic diversity and relationships because of its cost effectiveness, simple operation as well as the need of very little starting DNA template (Lin et al., 2009; Uysal et al., 2010). In addition, previous studies of evaluating the phylogenetic relationship of Korean Allium species using ISSR marker indicated that these markers were highly informative in Allium (Hao et al., 2002).

Recent advances in taxonomy and classification of Allium have shown that, there are about 135 species of Allium including 7 subgenera and 32 sections in Iran (Fritsch and Maroofi, 2010; Memariani et al., 2012; Fritsch and Abbasi, 2013). North-eastern part of Iran (Khorassan provinces) with about 35 species is one of the most important centres of diversity of genus Allium in the country (Memariani et al., 2007). Previously there have been some studies on the taxonomy of Allium (Fritsch et al., 2006; Fritsch and Abbasi, 2013), however, except for a few studies focusing on the diversity of one species (Abdoli et al., 2009; Ebrahimi et al., 2009), there has not been any reports corresponding to molecular genetic diversity and genetic relationship of Allium in Iran. The present study was designed to explore the genetic diversity and interspecific relationships of some Allium species in north-east Iran and to evaluate the potential of ISSR marker in detecting the genetic variability of native Alliums.

\section{Materials and Methods}

\section{Plant materials:}

A total of 32 accessions representing 11 species of Allium were collected from North Khorassan and Razavi Khorassan provinces, located in northeast of Iran during 2012-2013 (Table 1). The samples were identified based on morphological characteristics and diagnostic descriptions of the species in the relevant literature (Wendelbo, 1971; Fritsch and Abbasi, 2013). Modern concepts of infrageneric classification of the genus are based on Friesen et al. (2006), Fritsch et al. (2010), and Fritsch and Abbasi (2013).

\section{DNA isolation:}

Total genomic DNA was extracted based on CTAB method (Doyle and Doyle, 1990) using Accuprep genomic DNA extraction kit (Bioneer, Korea) following manufacturer's instructions. The relative purity and concentration of extracted DNA was estimated with spectroscopy and Lambda DNA (Thermo scientific, USA) using a known concentration as a reference.

\section{ISSR amplification:}

A set of 20 ISSR primers (University of British Colombia, Canada) was screened to generate the molecular profiles. Nine out of 20 primers were selected because of their consistent amplification and clear banding pattern. The primers sequences are listed in Table 2. PCR condition was optimized using different concentration of template DNA and $\mathrm{Mg}$ as well as different annealing temperature. PCR was done with $10 \mathrm{ng}$ template genomic DNA, $5 \mu \mathrm{l}$ of Taq DNA Polymerase, $2 \times$ Master Mix RED (Ampliqon, Denmark), $1.5 \mathrm{mM} \mathrm{MgCl}_{2}, 0.3 \mu \mathrm{M}$ primer, in a total volume of $10 \mu \mathrm{L}$. DNA amplification was performed on Ependorf Master cycler gradient (Ependorf Scientific, Germany) using the following condition: an initial denaturation step of $94^{\circ} \mathrm{C}$ for $5 \mathrm{~min}$ followed by 37 cycles of $94^{\circ} \mathrm{C}$ for $25 \mathrm{~s}$, optimized annealing temperature for $25 \mathrm{~s}, 72^{\circ} \mathrm{C}$ for $1 \mathrm{~min}$ and a final extension at $72^{\circ} \mathrm{C}$ for $5 \mathrm{~min}$. The amplification products were separated by electrophoresis on $1.5 \%(\mathrm{~W} / \mathrm{V})$ agarose gel in $0.5 \times$ tris-borate-ethylenediamin tetra acetic acid 


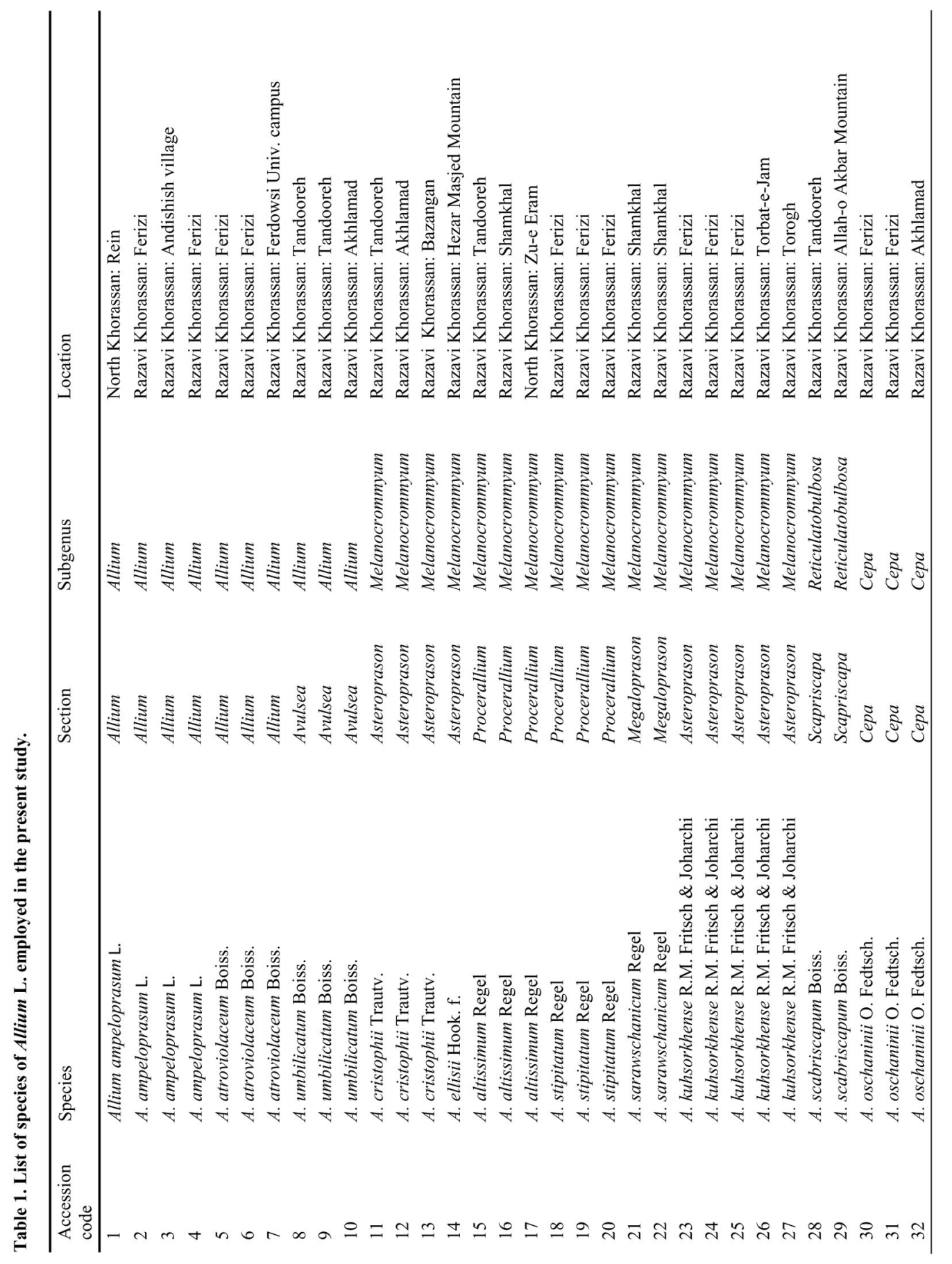


(TBE) buffer at $90 \mathrm{~V}$, stained with DNA green viewer (Pars Tous, Iran) and visualized under ultraviolet (UV) light in gel documentation system (UVI doc, UK). A 100 bp DNA ladder (Thermo scientific, USA) was used as molecular size standard. PCR amplification was repeated twice or sometimes more for each primer to ensure the reproducibility of the results.

Table 2. Characteristics of ISSR markers and genetic diversity statistics.

\begin{tabular}{llcccc}
\hline Primers & Sequence & $\mathrm{N}$ & $\mathrm{A}_{\mathrm{e}}$ & $\mathrm{H}_{\mathrm{e}}$ & $\mathrm{I}$ \\
\hline UBC 807 & AGA GAG AGA GAG AGA GT & 9 & $1.34(0.182)$ & $0.24(0.102)$ & $0.40(0.132)$ \\
UBC 808 & AGA GAG AGA GAG AGA GC & 7 & $1.23(0.103)$ & $0.18(0.068)$ & $0.32(0.095)$ \\
UBC 809 & AGA GAG AGA GAG AGA GG & 8 & $1.20(0.136)$ & $0.16(0.085)$ & $0.29(0.118)$ \\
UBC 811 & GAG AGA GAG AGA GAG AC & 7 & $1.21(0.091)$ & $0.17(0.061)$ & $0.31(0.085)$ \\
UBC 827 & ACA CAC ACA CAC ACA CG & 9 & $1.16(0.079)$ & $0.13(0.057)$ & $0.25(0.084)$ \\
UBC 834 & AGA GAG AGA GAG AGA GYT & 11 & $1.26(0.154)$ & $0.19(0.097)$ & $0.33(0.134)$ \\
UBC 835 & AGA GAG AGA GAG AGA GYC & 7 & $1.60(0.365)$ & $0.35(0.160)$ & $0.52(0.193)$ \\
UBC 840 & GAG AGA GAG AGA GAG AYT & 6 & $1.68(0.268)$ & $0.39(0.122)$ & $0.57(0.146)$ \\
UBC 855 & ACA CAC ACA CAC ACA CYT & 16 & $1.15(0.061)$ & $0.13(0.047)$ & $0.25(0.074)$ \\
Average & & 8.88 & 1.28 & 0.2 & 0.34 \\
\hline
\end{tabular}

$\mathrm{N}=$ number of bands; $\mathrm{A}_{\mathrm{e}}=$ number of effective alleles; $\mathrm{H}_{\mathrm{e}}=$ expected heterozigosity; $\mathrm{I}$ = Shannon's information index; Standard errors are in parentheses.

\section{Data analysis:}

The reproducible and well resolved fragments obtained from ISSR analysis were scored as binary code, viz. presence (1) and absence (0) of homologous bands. The binary data matrix was analyzed using NTSYS-PC version 2.1 software package (Rohlf, 2000). The pairwise genetic distances among all accessions was calculated based on Nei (1978) similarity coefficient. Genetic diversity $\left(\mathrm{H}_{\mathrm{e}}\right)$ was calculated per primer and for each species (except for Allium ellisii Hook. f. for which only one accession was available) using POPGENE software, version 1.32 (Yeh and Boyle, 1997). A dendrogram was constructed by using the unweighted pair group method with arithmetic mean (UPGMA) employing the SAHN (Sequential Agglomerative Hierarchical and Nested) module of NTSYS-PC to show a phenetic representation of genetic relationships as revealed by similarity coefficient. Percentage of polymorphic bands (PPB) was calculated by dividing the number of polymorphic bands by total number of bands surveyed.

\section{Results}

Nine ISSR primers generated 80 bands corresponding to an average of 8.8 bands per primer (Table 2). The fragment size varied from 100 to $2200 \mathrm{bp}$ and the number of bands ranged from 6 (UBC 840) to 16 (UBC 855). All of the 80 bands detected by ISSR primers were polymorphic among the individuals, i.e. the percentage of polymorphic bands was $100 \%$ for each primer. Considering all accessions, the average gene diversity, effective number of alleles and Shannon's information index was $0.2,1.28$ and 0.3 , respectively. The genetic diversity generated by each primer varied from 0.38 (primer UBC 840) to 0.12 (UBC 855). The average effective number of alleles and Shannon's information index was 1.28 and 0.34 , respectively. Among the 11 species, A. kuhsorkhense R.M. Fritsch \& Joharchi and A. ampeloprasum L. exhibited the highest variability (PPB: $42.5 \%$ and $37.5 \%, \mathrm{H}_{\mathrm{e}}: 0.18$ and 0.14 , respectively) whereas the species $A$. stipitatum Regel and A. sarawschanicum Regel presented the least variability (PPB: $12.5 \%$ and $16.25 \%$, and $\mathrm{H}_{\mathrm{e}}: 0.05$ and 0.07 , respectively) as shown in Table 3. 
A dendrogram generated based on Nei's genetic distances and UPGMA method revealed genetic relationships among Allium species and accessions (Fig. 1). The high cophenetic correlation $(\mathrm{r}=0.95)$ obtained indicating a good fit between the dendrogram clusters and the distance matrix. The dendrogram displayed four main groups corresponding to four subgenera: Allium, Melanocrommyum (Webb \& Berthel.) Rouy, Cepa (Mill.) Radić, and Reticulatobulbosa (Kamelin) N. Friesen. The most distant group comprised two accessions of A. scabriscapum with low genetic similarity coefficient $(\mathrm{Nei}=0.22)$ belonging to the subgenus Reticulatobulbosa. The only species present in section Cepa in this study was A. oschaninii B. Fedtsch. which formed a distinct group. The largest group corresponds to the subgenus Melanocrommyum. It, however, is divided into three subclusters each composing the species of the same section: section Procerallium comprises the accessions of A. altissimum and A. stipitatum; A. sarawshanicum Regel (section Megaloprason Wendelbo) makes a separate cluster; and A. cristophii Trautv. and A. ellisii comprise the section Asteroprason R.M. Fritsch (subsection Christophiana Tscholok.). Five accessions of $A$. kuhsorkhense with the highest genetic diversity (0.18) placed in section Asteroprason (subsection Asteroprason). Species belonging to the subgenus Allium formed a separate cluster. This cluster, however, is divided into two subclusters correspond to sections Allium and Avulsea F.O. Khassanov.

Table 3. Diversity parameters of Allium species.

\begin{tabular}{lccc}
\hline Species & Sample size & $\mathrm{H}_{\mathrm{e}}$ & PPB (\%) \\
\hline A. altissimum Regel & 3 & 0.1237 & 35 \\
A. ampeloprasum L. & 4 & 0.1445 & 37.5 \\
A. atroviolaceum Bioss. & 3 & 0.0802 & 21.25 \\
A. cristophii Trautv. & 3 & 0.0778 & 21.25 \\
A. kuhsorkhense R.M. Fritsch \& Joharchi & 5 & 0.1779 & 42.5 \\
A. oschaninii O. Fedtsch & 3 & 0.0904 & 26.25 \\
A. sarawschanicum Regel & 2 & 0.0673 & 16.25 \\
A. scabriscapum Bioss. & 2 & 0.0725 & 17.5 \\
A. stipitatum Regel & 3 & 0.0516 & 12.5 \\
A. umbilicatum Bioss. & 3 & 0.1102 & 25 \\
\hline
\end{tabular}

$\mathrm{H}_{\mathrm{e}}=$ expected heterozygosity; PPB = percentage of polymorphic bands.

\section{Discussion}

In the present study, nine ISSR primers yielded a total of 80 reproducibale bands with an average of 8.8 bands per primer, which was higher than in some other studies that have applied ISSR markers to Allium species. For example, in an analysis of 24 accessions of 13 Allium species, Son et al. (2012) detected 3 to 11 alleles per locus (average 7.5 alleles per primer) using 20 ISSR markers. In our study, a very high level of ISSR polymorphisms was detected in the Allium species indicating ISSR-PCR as a reliable technique for fingerprinting in the genus. ISSR markers have been widely employed in assessment of genetic relationships within and between plant species (Thul et al., 2012; Liu et al., 2013). Although there are not many reports on application of ISSR markers for analyzing the genetic relationships among Allium, the efficacy of ISSR markers on revealing the classification of Allium species has been strongly supported by previous studies (Hao et al., 2002; Son et al., 2012). Furthermore, the homology of ISSR bands between Allium species has been formerly confirmed by sequence analysis (Son et al., 2012). 
In this study, the genetic diversity of the endemic species $A$. kuhsorkhense, as well as the genetic relationships among Allium species were studied for the first time. The study revealed that A. kuhsorkhense is the most diverse species among the species employed in Khorassan. The accessions of A. kuhsorkhense were collected from nearly distant area. This endemic species has the widest distribution range among the other species of the endemic Allium section Asteroprason (Memariani et al., 2012). Hamrick (1989) stated that the wide distribution of a species can increase the rate of genetic diversity among the accessions. The clustered groups of Allium species clearly reflect the recent taxonomic concept of the genus at the subgenus and section levels. Subgenus Melanocrommyum comprises the largest group in the dendrogram. Three sections within the subgenus were detected and clearly identified, which is in consistent with previous studies (Gurushidze et al., 2008; Fritsch et al., 2010). In section Asteroprason, two main subclusters support its morphological classification into two subsections Christophiana and Asteroprason (Fritsch and Maroofi, 2010; Memariani et al., 2012).

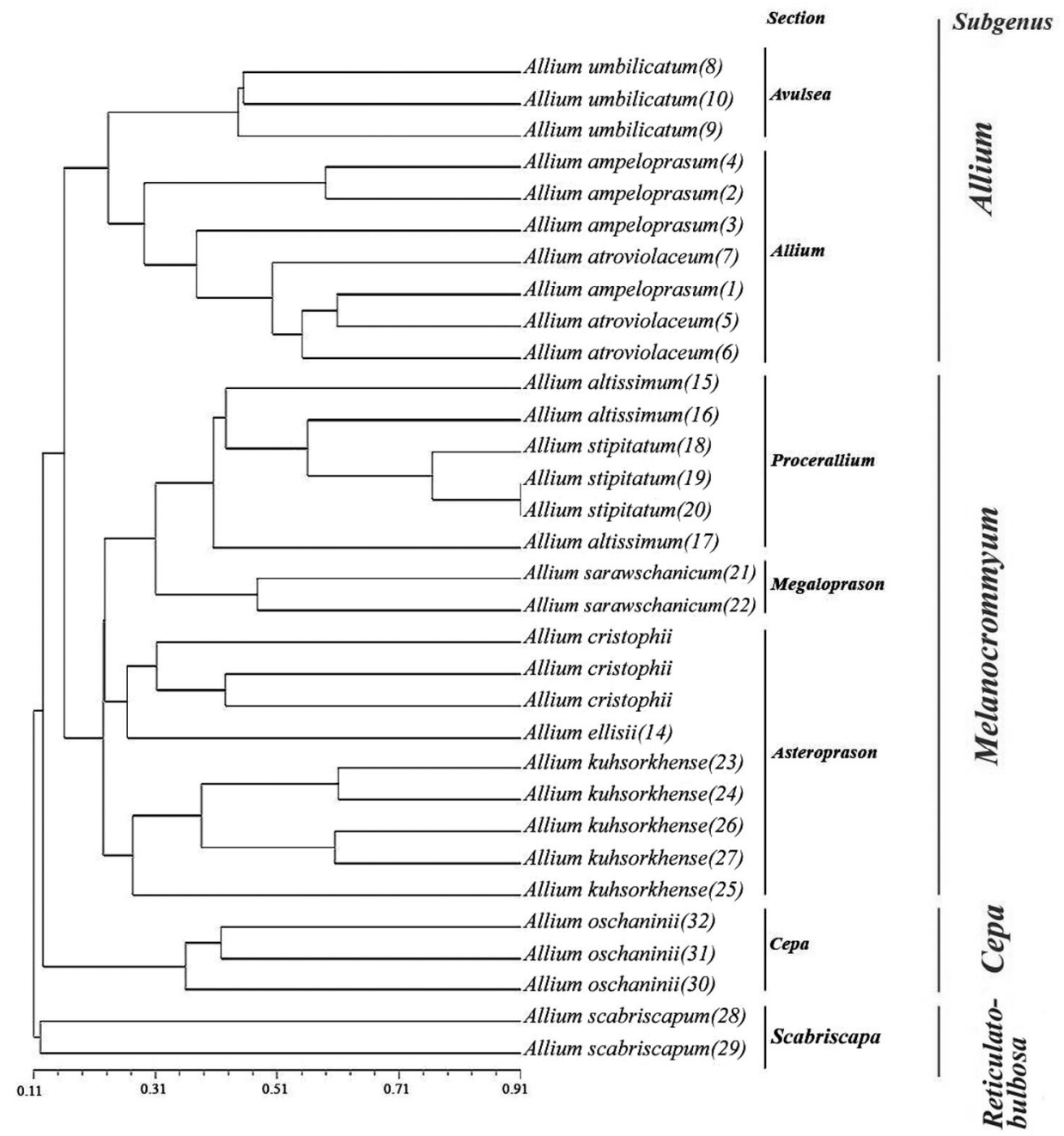

Fig. 1. UPGMA dendrogram showing species relationships of Allium based on Nei's genetic distance. The numbers in parentheses correspond accession codes of Table 1. 
Within all sections of subgenus Melanocrommyum, the species were clearly distinguished except for Procerallium R.M. Fritsch. In this section, the accessions of A. stipitatum positioned among the accessions of $A$. altissimum. Indeed these two species are morphologically very similar and difficult to be distinguished properly. However, it is accepted that A. altissimum is more slender and somewhat smaller than typical A. stipitatum possessing narrower and glabrous (or at the most only sparsely toothed) leaves, a smaller umbel, and more intensely coloured, sublinear, in late anthesis spirally enrolled tepals (Fritsch and Abbasi, 2013). Our ISSR analysis is in agreement with the molecular analyses based on ITS sequences of nuclear rDNA, sequences of the plastid $t r n \mathrm{~L}-t r n \mathrm{~F}$ region in which the cultivated strain of A. altissimum positioned among many accessions of Central Asian A. stipitatum underlining a high genetic similarity (Fritsch and Maroofi, 2010; Gurushidze et al., 2010). Based on our analysis, the accessions of $A$. ampeloprasum and A. atroviolaceum (section Allium) are similarly positioned among each other, however, are well-separated from the accessions of A. umblicatum Boiss. (section Avulsea). Hirschegger et al. (2010) found similar results for A. ampeloprasum group based on nuclear and chloroplast DNA sequences analyses.

ISSR markers were highly informative at the section level as well as at the species level in the genus Allium. The resulting dendrogram was found consistent with the modern taxonomic classification, confirming that ISSR marker data can be used for taxonomic studies in the genus Allium. Genetic variation among wild species may assist plant taxonomists, and also breeders in identifying and introducing valuable traits into new hybrids. The collection and inclusion of more accessions of endemic and newly described Allium species will be useful for confirming their infrageneric classification, especially in morphologically diverse subgenus Melanocrommyum and also in economically important species and their wild relatives in subgenus Allium (garlic and leek).

About one-third of Iranian Allium species are native to Khorassan-Kopetdagh floristic province, located in the northeast of Iran and partly in southern Turkmenistan which is a transitional zone connecting different floristic provinces of Irano-Turanian region. Several Allium species occur in the eastern or western limits of their distribution ranges in Khorassan-Kopetdagh as well as many narrow and local endemics (Wendelbo, 1971; Memariani et al., 2007, 2012). Molecular analyses on newly described and rare Allium species, especially using ISSR markers, may helpfully reveal their taxonomic position among the infrageneric classification of the genus. Moreover, the assessment of genetic diversity among populations of Allium species can help to prioritize conservation efforts in order to prevent the extinction of the rare and threatened taxa with lower genetic diversity and also effective conservation of the genetically variable taxa.

\section{Acknowledgement}

This work was supported by the Ferdowsi University of Mashhad (grant no. 17812).

\section{References}

Abdoli, M., Habibi-Khaniani, B., Baghalian, K., Shahnazi, S., Rassouli, H. and Badi, H.N. 2009. Classification of Iranian garlic (Allium sativum L.) ecotypes using RAPD marker. J. Med. Plants 8: 45-51.

APG III 2009. An update of the Angiosperm Phylogeny Group classification for the orders and families of flowering plants: APG III. Bot. J. Linn. Soc. 161: 105-121.

Chase, M.W., Reveal J.L. and Fay, M.F. 2009. A subfamilial classification for the expanded asparagalean families Amaryllidaceae, Asparagaceae and Xanthorrhoeaceae. Bot. J. Linn. Soc. 161: 132-136.

Doyle, J.J. and Doyle, J.L. 1990. A rapid total DNA preparation procedure for fresh plant tissue. Focus 12: $13-15$. 
Ebrahimi, R., Zamani, Z. and Kashi, A. 2009. Genetic diversity evaluation of wild Persian shallot (Allium hirtifolium Boiss.) using morphological and RAPD markers. Sci. Hortic. 119: 345-351.

Friesen, N. 1995. The genus Allium L. in the flora of Mongolia. Feddes Repert. 106: 59-81.

Friesen, N., Fritsch, R.M. and Blattner, F.R. 2006. Phylogeny and new intrageneric classification of Allium (Alliaceae) based on nuclear ribosomal DNA ITS sequences. Aliso 22: 372-395.

Fritsch, R.M. and Abbasi, M. (Eds) 2013. A taxonomic review of Allium subg Melanocrommyum in Iran. Halberstädter Druckhaus Gmb H, Gatersleben, Germany, 240 pp.

Fritsch. R.M. and Friesen, N. 2002. Evolution, domestication and taxonomy. In: Rabinowitch, H.D. and Currah, L. (Eds), Allium Crop Science: Recent Advances. CABI Publishing, Wallingford, UK, pp. 5-30.

Fritsch, R.M. and Maroofi, H. 2010. New species and new records of Allium L. (Alliaceae) from Iran. Phyton 50: $1-26$.

Fritsch, R.M., Blattner, F.R. and Gurushidze, M. 2010. New classification of Allium L. subg Melanocrommyum (Webb \& Berthel) Rouy (Alliaceae) based on molecular and morphological characters. Phyton 49: 145-220.

Gurushidze, M., Fritsch, R.M. and Blattner, F.R. 2008. Phylogenetic analysis of Allium subg Melanocrommyum infers cryptic species and demands a new sectional classification. Mol. Phylogenet. Evol. 49: 997-1007.

Gurushidze, M., Fritsch, R.M. and Blattner, F.R. 2010. Species-level phylogeny of Allium subgenus Melanocrommyum: Incomplete lineage sorting hybridization and $\operatorname{trn} \mathrm{F}$ gene duplication. Taxon 59: 829-840.

Hamrick, J.L. 1989. Isozymes and the analysis of genetic structure in plant populations. In: Soltis, D.E. and Soltis, P.S. (Eds), Isozymes in Plant Biology. Dioscorides Press, Portland, Oregon, USA, pp. 87-105.

Hirschegger, P., Jakse, J., Trontelj, P. and Bohanec, B. 2010. Origins of Allium ampeloprasum horticultural groups and a molecular phylogeny of the section Allium (Allium: Alliaceae). Mol. Phylogenet. Evol. 54: 488-497.

Hao, G., Lee, D.H., Lee, J.S. and Lee, N.S. 2002. A study of taxonomical relationships among species of Korean Allium sect Sacculiferum (Alliaceae) and related species using inter-simple sequence repeat (ISSR) markers. Bot. Bull. Acad. Sin. 43: 63-68.

Khassanov, F.O. and Fritsch, R.M. 1994. New taxa in Allium L. subgen. Melanocrommyum (Webb \& Berth.) Rouy from Central Asia. Linzer Biologische Beitra 26: 965-990.

Kovtonyuk, N.K., Barkalov, V.J.U. and Friesen, N. 2009. Synopsis of the family Alliaceae Borkh. (onions) of Asian parts of Russia. Turczaninowia 12: 31-39.

Li, Q.Q., Zhou, S.D., He, X.J., Yu, Y., Zhang, Y.C. and Wei, X.Q. 2010. Phylogeny and biogeography of Allium (Amaryllidaceae: Allieae) based on nuclear ribosomal internal transcribed spacer and chloroplast rps16 sequences focusing on the inclusion of species endemic to China. Ann. Bot. 106: 709-733.

Lin, X.C., Ruan, X.S., Lou, Y.F., Guo, X.Q. and Fang, W. 2009. Genetic similarity among cultivars of Phyllostachys pubescens. Plant Syst. Evol. 277: 67-73.

Liu, Y., Zhang, J.M., Wang, X.G., Liu, F. and Shen, Z.B. 2013. Genetic diversity in Vicia amoena (Fabaceae) germplasm resource in China using SRAP and ISSR markers. Biochem. Syst. Ecol. 51: 86-93.

Mathew, B. 1996. A review of Allium section Allium. Royal Botanic Gardens, Kew, UK, 176 pp.

Matin, F. 1992. The genus Allium in Iran, diversity, distribution and endemism. In: Hanelt, P., Hammer, K. and Knüpffer, H. (Eds), The genus Allium - Taxonomic Problems and Genetic Resources. Proc. Int. Symp. Gatersleben, June 11-13, 1991. IPK, Gatersleben, pp. 193-194.

Memariani, F., Joharchi, M.R. and Khassanov, F.O. 2007. Allium L. subgen. Rhizirideum sensu lato in Iran, two new records and a synopsis of taxonomy and phytogeography. Iran. J. Bot. 13(1): 12-20.

Memariani, F., Joharchi, M.R. and Arjmandi, A.A. 2012. Allium aladaghense (Amaryllidaceae: Allieae) a new species of section Asteroprason from northeast of Iran. Phytotaxa 56: 28-34.

Mes, T.H., Friesen, N., Fritsch, R.M., Klaas, M. and Bachmann, K. 1997. Criteria for sampling in Allium based on chloroplast DNA PCR-RFLPs. System. Bot. 22: 701-712.

Mes, T.H, Fritsch, R.M., Pollner, S. and Bachmann, K. 1999. Evolution of the chloroplast genome and polymorphic ITS regions in Allium subg Melanocrommyum. Genome 42: 237-247. 
Mukherjee, A., Sikdar, B., Ghosh, B., Banerjee, A., Ghosh, E., Bhattacharya, M. and Roy, S.C. 2013. RAPD and ISSR analysis of some economically important species, varieties and cultivars of the genus Allium (Alliaceae). Turk. J. Bot. 37: 605-618.

Nei, M. 1978. Estimation of average heterozygosity and genetic distance from a small number of individuals. Genetics 89: 583-590.

Rabinowitch, H.D. and Brewster, J.L. 1990. Onions and allied crops. Vol. 1. Botany, Physiology and Genetics. CRC Press, Boca Raton, FL, 288 pp.

Rabinowitch, H.D. and Currah, L. 2002. Allium Crop Science: Recent Advances. CAB International Wallingford, UK, $515 \mathrm{pp}$.

Reveal, J.L. and Chase, M.W. 2011. APG III: Bibliographical Information and Synonymy of Magnoliidae. Phytotaxa 19: 71-134.

Rohlf, F.J. 2000. NTSYSpc: Numerical taxonomy and multivariate analysis system version 2.1. Exeter Publishing, Setauket, NY, 38 pp.

Son, J.H., Park, K.C., Lee, I., Kim, J.H. and Kim, N.S. 2012. Species relationships among Allium species by ISSR analysis. Hort. Environ. Biotechnol. 53: 256-262.

Thul, S.T., Darokar, M.P., Shasany, A.K. and Khanuja, S.P. 2012. Molecular profiling for genetic variability in Capsicum species based on ISSR and RAPD markers. Mol. Biotechnol. 51: 137-147.

Uysal, H., Fu, Y.B., Kurt, O., Peterson, G.W., Diederichsen, A. and Kusters, P. 2010. Genetic diversity of cultivated flax (Linum usitatissimum L.) and its wild progenitor pale flax (Linum bienne Mill.) as revealed by ISSR markers. Genet. Resour. Crop Evol. 57: 1109-1119.

Wendelbo, P. 1971. Alliaceae. In: Rechinger, K.H. (Ed.), Flora Iranica, Vol. 76. Akademische Druck-und Verlagsanstalt, Graz, Austria, $100 \mathrm{pp}$.

Yeh, F.C. and Boyle, T.J.B. 1997. Population genetic analysis of codominant and dominant markers and quantitative traits. Belg. J. Bot. 129: 157-163.

(Manuscript received on 1 November 2014; revised on 11 June 2015) 